\title{
Prevalence and Factors Associated with Mortality among Chest Injury Patients Admitted at Muhimbili National Hospital in Dar es Salaam, Tanzania
}

\author{
Janeth Stanslaus Masuma1, Respicious Lwezimula Boniface ${ }^{1,2,3^{*}}$, Edwin Rwebugisa Lugazia1,4 \\ ${ }^{1}$ Muhimbili University of Health and Allied Sciences (MUHAS), Dar es Salaam, Tanzania \\ ${ }^{2}$ Muhimbili Orthopaedic Institute (MOI), Dar es Salaam, Tanzania \\ ${ }^{3}$ Injury Control Centre Tanzania (ICCT), Dar es Salaam, Tanzania \\ ${ }^{4}$ Jakaya Kikwete Cardiac Institute, Dar es Salaam, Tanzania \\ Email: ^respiciousboniface@yahoo.com, ${ }^{\star}$ respiciousboniface@gmail.com
}

How to cite this paper: Masuma, J.S., Boniface, R.L. and Lugazia, E.R. (2021) Prevalence and Factors Associated with Mortality among Chest Injury Patients Admitted at Muhimbili National Hospital in Dar es Salaam, Tanzania. International Journal of Clinical Medicine, 12, 364-376. https://doi.org/10.4236/ijcm.2021.129033

Received: July 28, 2021

Accepted: September 11, 2021

Published: September 14, 2021

Copyright $\odot 2021$ by author(s) and Scientific Research Publishing Inc. This work is licensed under the Creative Commons Attribution International License (CC BY 4.0).

http://creativecommons.org/licenses/by/4.0/

\begin{abstract}
Introduction: Accidents represent a significant proportional of non-communicable disease in the current century, and chest injury is common. However, management and outcome of these injuries is poor in low resource setting like Tanzania. The aim of this study was to determine the prevalence and factors associated with mortality among chest injury patients at a tertiary level health facility in Tanzania. Method: A prospective Cross-Sectional study of chest injuries among trauma patients attended at Muhimbili National Hospital between September 2019 and February 2020. Results: A total of 282 trauma patients were seen, out of which 51/282 (18.1\%) sustained chest injury. Road Traffic Crashes were the leading cause of chest injury 41/51 (80.4\%). Majority 17/51 (33.3\%) presented with lung contusion, followed by pneumohemothorax and rib fractures each $8 / 51$ (15.7\%). Most of the patients $27 / 51(52.9 \%)$ were managed by tube thoracostomy and $42.1 \%$ conservatively. Mortality was 11/51 (21.6\%). Independent factors associated with mortality were: Associated injuries (Odds Ratio (OR) 0.07, 95\% CI $0.01-1.16, \mathrm{p}=$ 0.02), Multimodal analgesia (Odds Ratio (OR) $0.22,95 \%$ CI $0.05-0.98, \mathrm{p}=$ 0.05), more than 24 hours to treatment (Odds Ratio (OR) 5.53, 95\% CI 1.25 24.3, $\mathrm{p}=0.02$ ), Bilateral chest involvement (Odds Ratio (OR) 4.61, 95\% CI $1.12-18.7, \mathrm{p}=0.02$ ), and Invasive ventilation (Odds Ratio (OR) 31.5, 95\% CI $4.47-53.8, \mathrm{p}=0.00)$. Conclusion: Chest injuries prevail significantly among trauma patients in Tanzania, mostly due to road traffic crashes. Injury preventive measures especially for road traffic crashes need to be reinforced, and establishment of chest injury management protocol in Tanzania.
\end{abstract}




\section{Keywords}

Chest Injury, Road Traffic Crashes, Tanzania

\section{Introduction}

Trauma continues to be associated with high morbidity and mortality both in developed and developing countries [1]. Chest Injuries account for $10 \%$ of Global trauma admission and 25\% of trauma related deaths [2] [3]. Studies have revealed the prevalence of chest injury to be varying from different parts of the world, being high in low- and middle-income countries and low in developed countries [4], this is mostly due to variations in preventive measures of trauma. The estimated mortality due to chest injuries in Tanzania is 40\% [5], and continues to be the commonest cause of surgical admissions with significantly high morbidity and mortality [6].

Causes and pattern of chest injuries vary in different parts of the world due to socio-economic status variations, the commonest cause being road traffic crashes [7] [8], majorities of victims being in the active age group sustaining blunt chest injury. Like other developing nations in the world, Tanzania has a significantly high rate of traffic related deaths and disabilities. A hospital-based injury surveillance [9] revealed traffic crashes to be the leading cause of injuries accounting for $47.5 \%$ of all injuries seen and $60.5 \%$ of injuries mortality. Chest injury is second only to head injury as a major cause of morbidity and mortality in Tanzania emergency rooms, and this can be explained by the lack of organized pre-hospital care, severity of injuries and late management of patients [10].

Management option depends on type of chest injury and clinical presentation of the patients. Patients with pneumothorax, haemothorax or both would improve on tube thoracostomy. Other patients would require mechanical ventilation, appropriate analgesics management, supportive therapy and critical care observation [11] [12]. It is therefore necessary for accurate, early identification and aggressive management of chest injuries, along with prompt treatment of associated injuries for optimal patient outcome. This study was therefore conducted to help us understand the magnitude and management of chest injury patients at a tertiary level health facility in Tanzania. The result of this study will help in establishing prevention strategies as well as management protocol to better assess, treat and monitor chest injury patients with a view of improving patient outcomes.

\section{Methodology}

Study setting: data were collected from Muhimbili National Hospital emergency medicine department. It is the main government tertiary hospital of Tanzania, located along Dar es Salaam region in Tanzania and has the capacity 1500 beds. It is a referral centre for all other hospitals in Dar es Salaam (over 5 million 
inhabitants) and Tanzania at large, and is also a teaching hospital for Muhimbili University of Health and Allied Sciences.

Study design: A prospective Cross-Sectional study was conducted.

Study population: the study population comprised of chest injury patients attended at Muhimbili National Hospital emergency department between September 2019 and February 2020.

Data collection and management: a structured questionnaire designed by principal investigators was used to collect information from the study participants in a face-to-face interview, and from medical records. Questions were drawn from previously conducted studies and a pilot study was conducted to ensure validity and reliability of the data collection tool. A questionnaire had 18 items including: socio-demographic characteristics, mode of injury, type of injury, severity of injury, treatment pattern and patient's outcome (Appendix). Data were double-entered into Excel (Microsoft $\hat{A}^{\otimes}$ Excel, Seattle Washington), Statistical analysis was conducted using Statistical Package for Social Sciences (SPSS) version 23 (IBM Corp. IBM SPSS Statistics for Windows [Internet]. Armonk, NY: IBM Corp; 2017).

Statistical analysis. all variables were categorized and described using frequency distribution. Chi-square test was used for bivariate analysis and those variables with observed frequency less than five Fisher's exact test was applied. A variable with ( $\mathrm{p} \leq 0.05)$ with mortality was considered to be statistically significant. Variables that demonstrated significant bivariate association with mortality were entered into the multivariate logistic regression modal to assess independent effects. Parameter of measurement to assess association was odds ratio.

Ethical consideration: ethical approval for the study was obtained from the Muhimbili University of Health and Allied Sciences Research Ethics Committee. An informed written consent was sought from patients or relatives.

\section{Results}

A total of 282 trauma patients were seen between September 2019 and February 2020. Chest injuries accounted for 51/282 (18.1\%) of patients, majority (72.5\%) belonged to the productive age group (20 to 39 years), and $74.5 \%$ were males, with a male to female ratio of 3:1 (Table 1).

\subsection{Mechanism of Injury}

Road traffic crashes (80.4\%) were responsible for the majority of Chest injuries, Assault (15.7\%) and fall from height (3.9\%).

\subsection{Type of Chest Injuries}

Blunt trauma accounted for $88.2 \%$ of the chest injuries, $11.8 \%$ were penetrating injuries. Lung contusion was the commonest (33.3\%) followed by, Pneumohemothorax and Rib fractures each (15.7\%). Pneumothorax was present in $11.7 \%$ of the patients whereas haemothorax was present in $7.8 \%$ of the cases. 
Two patients (3.9\%) had an injury to the heart and 3.9\% had a Flail chest (Table 2). Majority of patients (52.9\%) had tube thoracostomy done, and $42.1 \%$ managed conservatively.

Table 1. Social demographic characteristics.

\begin{tabular}{|c|c|c|}
\hline Sex & Frequency (n) & Percentage (\%) \\
\hline Male & 38 & 74.5 \\
\hline Female & 13 & 25.5 \\
\hline Total & 51 & 100 \\
\hline \multicolumn{3}{|l|}{ Marital status } \\
\hline Single & 27 & 52.9 \\
\hline Married & 21 & 41.2 \\
\hline Others & 3 & 5.9 \\
\hline Total & 51 & 100 \\
\hline \multicolumn{3}{|l|}{ Education } \\
\hline Primary school & 15 & 29.4 \\
\hline Secondary school & 18 & 35.3 \\
\hline High level & 13 & 25.5 \\
\hline No formal education & 5 & 9.8 \\
\hline Total & 51 & 100 \\
\hline \multicolumn{3}{|l|}{ Age (Years) } \\
\hline 1 to 19 & 2 & 3.9 \\
\hline 20 to 39 & 37 & 72.5 \\
\hline 40 to 59 & 11 & 21.6 \\
\hline 60 and above & 1 & 2 \\
\hline Total & 51 & 100 \\
\hline
\end{tabular}

Table 2. Type of chest injury.

\begin{tabular}{cc}
\hline Chest injury type & Frequency (percentage) \\
\hline Pneumothorax & $6(11.7)$ \\
Hemothorax & $4(7.8)$ \\
Pneumohemothorax & $8(15.7)$ \\
Rib fracture & $8(15.7)$ \\
Lung contusion & $17(33.3)$ \\
Clavicle fracture & $4(7.8)$ \\
Cardiac injury & $2(3.9)$ \\
Flail chest & $2(3.9)$ \\
\hline
\end{tabular}




\subsection{Factors Associated with Mortality}

Of the 51 patients seen $78.4 \%$ survived, and $21.6 \%$ died. The following factors were significantly associated with mortality after bivariate analysis: Associated injuries accounted for $63.6 \%$ of mortality (p-value 0.014 ), serious and critical injured patients each accounted for $36.4 \%$ of mortality (p-value 0.009 ), using a single type of analgesia accounted for $72.7 \%$ of mortality (p-value 0.038 ), receiving medical attention 24 hours after injury contributed $72.7 \%$ of mortality (p-value 0.016 ). Bilateral chest involvement contributed $63.6 \%$ of mortality ( $\mathrm{p}$-value 0.026$)$ and invasively ventilated patients $81.8 \%$ of mortality ( $\mathrm{p}$-value 0.00) (Table 3).

Table 3. Factors associated with mortality.

\begin{tabular}{|c|c|c|c|c|c|}
\hline Factor & Death N (\%) & No death $\mathrm{N}(\%)$ & P-value & Multivariate OR ( $95 \% \mathrm{CI})$ & $\mathrm{P}$-value \\
\hline \multicolumn{6}{|l|}{ Age (Years) } \\
\hline $1-19$ & $1(50)$ & $1(50)$ & \multirow{4}{*}{0.66} & & \\
\hline $20-39$ & $7(18.9)$ & $30(81.1)$ & & & \\
\hline $40-59$ & $3(27.3)$ & $8(72.7)$ & & & \\
\hline 60 and above & $0(0.0)$ & $1(100)$ & & & \\
\hline \multicolumn{6}{|l|}{ Sex } \\
\hline Male & $9(23.7)$ & $29(76.3)$ & \multirow{2}{*}{0.76} & & \\
\hline Female & $2(15.4)$ & $11(84.6)$ & & & \\
\hline \multicolumn{6}{|l|}{ Associated injuries } \\
\hline Present & $7(15.91)$ & 37 (84.09) & \multirow{2}{*}{$0.014^{++}$} & 1 & \\
\hline Not present & $4(57.14)$ & $3(32.86)$ & & $0.07(0.01-1.16)$ & $0.024^{++}$ \\
\hline \multicolumn{6}{|l|}{ AIS range } \\
\hline Moderate & $1(14.29)$ & $6(85.71)$ & \multirow{4}{*}{$0.009^{++}$} & 1 & \\
\hline Serious & $4(13.33)$ & $26(86.67)$ & & $0.92(0.08-9.8)$ & 0.09 \\
\hline Severe & $2(22.22)$ & $7(77.78)$ & & $1.71(1.22-23.9)$ & 0.68 \\
\hline Critical & $4(80.00)$ & $1(20.00)$ & & $24(1.14-50.5)$ & $0.04^{++}$ \\
\hline \multicolumn{6}{|l|}{ Pain management } \\
\hline Single analgesia & $8(34.78)$ & $15(65.22)$ & \multirow{2}{*}{$0.038^{++}$} & 1 & \\
\hline More than 1 analgesia & $3(10.71)$ & $25(89.29)$ & & $0.22(0.05-0.98)$ & $0.05^{++}$ \\
\hline \multicolumn{6}{|c|}{ Time to treatment (hours) } \\
\hline Less than 24 & $3(10.00)$ & $27(90.00)$ & \multirow{2}{*}{$0.016^{++}$} & 1 & \\
\hline 24 and above & $8(38.89)$ & $13(61.90)$ & & $5.53(1.25-24.3)$ & $0.00^{++}$ \\
\hline \multicolumn{6}{|l|}{ Chest involvement } \\
\hline Unilateral & $4(12.12)$ & $29(87.88)$ & \multirow{2}{*}{$0.026^{++}$} & 1 & \\
\hline Bilateral & $7(38.89)$ & $11(61.11)$ & & $4.61(1.12-18.7)$ & $0.02^{++}$ \\
\hline \multicolumn{6}{|l|}{ Assisted ventilation } \\
\hline Non invasive & $2(5.12)$ & $37(94.9)$ & \multirow{2}{*}{$0.00^{++}$} & 1 & \\
\hline Invasive & $9(75)$ & $3(25)$ & & $31.5(4.47-53.8)$ & $0.00^{++}$ \\
\hline
\end{tabular}

AIS $=$ abbreviated injury severity score; ${ }^{++} \mathrm{P}$-value $\leq 0.05$. 
The following factors remained statistically significant after multivariate logistic regression analysis: Associated injuries, critical injury, analgesia mode, time to treatment, bilateral chest involvement and invasive ventilation. Those with no associated injuries were $93 \%$ less likely to die than those who had associated injuries. Critical injured patients were 24 times more likely to die than moderately injured patients. Presenting to hospital more than 24 hours post-injury were 5.5 times more likely to die compared to those who presented to hospital within 24 hours post-injury. Those with bilateral chest involvement were 4.6 times more likely to die than those who had unilateral chest involvement. The risk of death was 31.5 times greater in those who needed invasive ventilation than non-invasive ventilation, and it was $78 \%$ less in those who had more than one analgesia than those managed by a single analgesia (Table 3 ).

\section{Discussion}

This study aimed at finding the prevalence of chest injuries among trauma patients and the predictors of mortality. The prevalence of chest injuries in this study was $18.1 \%$, similar to what has been reported in other sub-Saharan African countries [11] [12]. This study also revealed majority of injured patients to be males in productive age group, with a male to female ratio of 3:1 similar to other studies in Africa and elsewhere [13] [14]. Male predominance is attributed to their active involvement in the risky daily activities for living, including speeding motorcycles, vehicles, violence and falls. Majority of injured victims in this study were in economically active group (20 - 39 years), this has a direct impact economically on individuals, families, communities and the country at large hence the need for health education aimed at reducing the incidence and severity of trauma targeting this group of people.

Road traffic crashes (80.4\%) were responsible for the majority of Chest injuries in this study. Other studies conducted in Tanzania [6] [9] [10] have revealed similar results. Road Traffic Crashes especially motorcycles continue to be a leading cause of trauma and admission of most hospitals in Tanzania, hence a call for road traffic crash prevention measures. World Health Organization notes the escalating road traffic crashes in developing countries, some of the major reasons for this trend are: increasing motorization, poor road infrastructure, not complying to traffic laws and driving or riding under the influence of recreational substances [15] [16].

Majority in this study were blunt injury (88.2\%), this is higher than $55.7 \%$ reported by Mwesigwa et al. in Mbarara, Uganda [17], and is in contrast to two other studies done by Ali, Gali [18] and Maxwell [19], which revealed penetrating injuries to be $61.5 \%$ and $77 \%$ respectively. Lung contusion $(33.3 \%)$ was the leading clinical type of chest injury seen in this study; other studies however have reported rib fractures to be the commonest type of chest injury [17] [20] [21]. Otieno et al. reported hemopneumothorax to be the commonest injury sustained in the Kenyan rural population [22]. 
Two patients (3.9\%) had Cardiac Injury in this study, similar to what was reported by Masaga et al. [20], in which they reported few patients with life threatening conditions such as oesophageal perforation, cardiac injury and diaphragmatic rupture. Majority of victims sustaining these types of severe injuries die at the site of accidents and hence don't make it to hospitals.

Majorities $58.8 \%$ of injury victims were attended in within 24 hours from injury in this study, and were more likely to survive than those who received medical attention more than 24 hours from injury. Delay in receiving medical attention minimises the chance of survival for the injured patients, especially severely injured patients. This calls for proper pre-hospital emergency care system and ambulance services in developing countries like Tanzania if severely injured patients are to survive.

Most of the patients (52.9\%) in this study, required a chest tube thoracostomy and others $(42.1 \%)$ were managed conservatively by (observation, analgesia and antibiotics and chest physiotherapy), similar to what has been reported in other studies done elsewhere [6] [23]. It is also reported in studies done in developed countries that observation, chest tube placement, adequate volume replacement, occasional respiratory support and serial chest X-rays are the only treatment required in $80 \%-85 \%$ of the patients [24] [25].

In this study, 23 (45\%) patients were given one type of pain medication and 28 (55\%) were given more than one type of pain medication. Pain management option significantly influenced survival, those who received more than 1 type of pain medication were more likely to survive as compared to those who received a single type of pain medication. Results similar to Annalise et al. in her review on treatment of chest trauma and their impact [26], in which it was revealed that using more than one option of pain medication improved the outcome of thoracic injury patients. Other studies have demonstrated a big role of regional anaesthesia with intercostal blockade, thoracic epidurals and paravertebral blockades in significant reduction of pain in chest injury patients [6] [27]. The main options in our setting were systemic medication (Opioids, NSAIDS and paraceta$\mathrm{mol}$ ), which have been reported in literatures to be insufficient for optimal pain control [28]. Optimal pain control in chest injury patients prevents splinting of the diaphragm and atelectasis.

In this study, $12(23.5 \%)$ patients needed invasive ventilation and were 31.5 times more likely to die than non-invasive ventilated patients. Patients with blunt or penetrating chest trauma may require mechanical ventilation. Lung protective ventilation strategies have to be applied otherwise it is associated with attributable mortality if it is set incorrectly [29], hence a need for mechanical ventilation modes training for personnel's working in our emergency rooms and intensive care units.

The mortality rate in this study was $21.6 \%$ which is almost similar to what was reported by Massaga et al. 24.2\% [20], but higher compared to what was reported in other studies done elsewhere [6] [17]. Statistically significant predictors of mortality in this study included associated injuries, analgesia mode, time 
to treatment, critical injury, bilateral chest involvement and invasive ventilation, results almost similar to what have been reported in other studies done elsewhere [6] [17] [20]. There is therefore a need for management improvement strategies targeting these predictors of mortality in order to improve outcome of chest injury patients in Tanzania, including establishing trauma care system in the country.

In considering the findings of this study it is important to bear in mind the following limitations: firstly, this was a single centre study with small number of patients, and the time frame of the study was short, hence it may not reflect what is happening in other centres. Secondly, data collectors not collecting all data and so some are missing. Thirdly, information bias from participants and data collectors may have affected the quality of data.

\section{Conclusion}

The results of this study provide valuable insight into the burden and management of Chest injury in Tanzania hospitals. It points to the need of establishing management guidelines for chest trauma in both pre-hospital and in-hospital setting. Since most of the chest trauma cases are due to Road traffic crashes, there is an urgent need of road traffic crash preventive measures to help reduce the frequency of chest injury in our population. Public awareness campaigns concerning road safety rules are needed as well as roads improvement.

\section{What Is Known about This Topic?}

- Accidents represent a significant proportional of non-communicable disease in Tanzania.

- Majority are due to road traffic crashes.

- Chest injury is among the common injuries sustained by the victims.

\section{What This Study Adds}

- This study provides valuable insight into the burden and management of Chest injury in Tanzania hospitals.

- It also points to the need of establishing management guidelines for chest trauma in both pre-hospital and in-hospital settings.

\section{Authors' Contributions}

Janeth Stanslaus Masuma, Respicious Lwezimula Boniface and Edwin Rwebugisa Lugazia conceived and designed the study. Janeth Stanslaus Masuma undertook the data collection and statistical analysis and wrote the first draft of the manuscript. All authors contributed to intellectual content and approved the final manuscript.

\section{Acknowledgements}

We are grateful to the management and workers of Muhimbili National Hospital 
for their cooperation. This work was supported by Muhimbili University of Health and Allied Sciences (MUHAS), Muhimbili National Hospital and Muhimbili Orthopaedic Institute.

\section{Conflicts of Interest}

The authors declare no conflicts of interest regarding the publication of this paper.

\section{References}

[1] Sharma, P.P., Jhanwar, A., Sharma, D. and Sharma, S. (2016) Blunt Trauma Chest: Our Experience at Rural Tertiary Care Centre. International Surgery Journal, 3, 261-265. https://doi.org/10.18203/2349-2902.isj20160239

[2] Miller, D.L. and Mansour, K.A. (2007) Blunt Traumatic Chest Injuries. Thoracic Surgery Clinics, 17, 57-61. https://doi.org/10.1016/j.thorsurg.2007.03.017

[3] Okugbo, S.U., Okoro, E. and Irhibogbe, P.E. (2012) Functional Concepts in the Management of Simple Chest Injuries. Journal of West African College of Surgeons, 2, 74-84.

[4] Søreide, K. (2009) Epidemiology of Major Trauma. British Journal of Surgery, 96, 697-698. https://doi.org/10.1002/bjs.6643

[5] Taché, S., Mbembati, N., Marshall, N., Tendick, F., Mkony, C. and O'Sullivan, P. (2009) Addressing Gaps in Surgical Skills Training by Means of Low-Cost Simulation at Muhimbili University in Tanzania. Human Resources for Health, 7, Article No. 64. https://doi.org/10.1186/1478-4491-7-64

[6] Lema, M.K., Chalya, P.L., Mabula, J.B. and Mahalu, W. (2011) Pattern and Outcome of Chest Injuries at Bugando Medical Centre in Northwestern Tanzania. Journal of Cardiothoracic Surgery, 6, Article No. 7. https://doi.org/10.1186/1749-8090-6-7

[7] Frimpong-Boateng, K. and Amoati, A.B.G. (2000) Chest Injuries in Ghana. West African Journal of Medicine, 19, 175.

[8] Inci, I., Ozçelik, I., Tacyildiz, O., Nizam, N., Eren, G. and Ozen, D.B. (1998) Penetrating Chest Injuries: Unusually High Incidence of High Velocity Gunshot Wounds in Civilian Practice. World Journal of Surgery, 22, 438-442. https://doi.org/10.1007/s002689900412

[9] Boniface, R., Museru, L., Munthali, V. and Lett, R. (2013) Injury Experience in Tanzania-Need for Intervention. The East African Medical Journal, 90, 171-179.

[10] Boniface, R., Museru, L., Kiloloma, O. and Munthali, V. (2016) Factors associated with road traffic injuries in Tanzania. Pan African Medical Journal, 23, Article No 46. https://doi.org/10.11604/pamj.2016.23.46.7487

[11] Galukande, M., Jombwe, J., Fualal, J. and Gakwaya, A. (2009) Boda-Boda Injuries a Health Problem and a Burden of Disease in Uganda: A Tertiary Hospital Survey. East and Central African Journal of Surgery, 14, 33-37.

[12] Saidi, H.S. and Nyaikamo, J. (2002) Gunshot Injuries as Seen at Agakhan Hospital Kenya. East African Medical Journal, 79, 188-192. https://doi.org/10.4314/eamj.v79i4.8876

[13] Museru, L.M., Mcharo, C.N. and Leshabari, M.T. (2002) Road Traffic Accident in Tanzania: A Ten-Year Epidemiological Appraisal. East and Central African Journal of Surgery, 7, 23-26. 
[14] Muyembe, V.M. and Suleman, N. (1998) Head injuries at a Provincial General Hospital in Kenya. East African Medical Journal, 75, 364-369.

[15] World Health Organization (2011) Motorcycle-Related Road Traffic Crashes in Kenya: Facts and Figures.

https://www.who.int/violence_injury_prevention/road_traffic/countrywork/factshe et_kenya.pdf

[16] World Health Organization (2004) World Report on Road Traffic Injury Prevention. World Health Organization, Geneva.

https://www.who.int/publications/i/item/world-report-on-road-traffic-injury-preve ntion

[17] Mwesigwa, M.M., Bitariho, D. and Twesigye., D. (2016) Patterns and Short-Term Outcomes of Chest Injuries at Mbarara Regional Referral Hospital in Uganda. East and Central African Journal of Surgery, 21, 28-35.

https://doi.org/10.4314/ecajs.v21i3.6

[18] Ali, N. and Gali, B.M. (2004) Pattern and Management of Chest Injury in Maiduguri, Nigeria. Annals of African Medicine, 13, 181-184.

[19] Maxwell, R.A., Campbell, D.J., Fabian, T.C., Croce, M.A., Luchette, F.A., Kerwin, A.J., et al. (2004) Use of Presumptive Antibiotics Following Tube Thoracostomy for Traumatic Haemopneumothorax in the Prevention of Empyema and Pneumonia-A Multi-Center Trial. Journal of Trauma, 57, 742-748. https://doi.org/10.1097/01.TA.0000147481.42186.42

[20] Masaga, F.A. and Mchembe, M. (2010) The Pattern and Management of Chest trauma at Muhimbili National Hospital, Dar es Salaam. East and Central African Journal of Surgery, 15, 124-129.

[21] Mohan, A., Singh, G. and Kohli, A. (2006) Chest Trauma in Jammu Region an Institutional Study. Indian Journal of Thoracic and Cardiovascular Surgery, 22, 219-222. https://doi.org/10.1007/s12055-006-0006-1

[22] Otieno, T., Woodfield, J.C., Bird, P. and Hill, A.G. (2004) Trauma in Rural Kenya. Injury, 35, 1228-1233. https://doi.org/10.1016/j.injury.2004.03.013

[23] Saeed, A.Y., Hamza, A.A. and Ismail, O.M. (2015) Pattern and Management Outcome of Chest Injuries in Omdurman Teaching Hospital Sudan. Global Journal of Medical Research, 15, 5-9.

[24] Bastos, R., Baisden, C.E., Harker, L. and Calhoon, J.H. (2008) Penetrating Thoracic Trauma. Seminars in Thoracic and Cardiovascular Surgery, 20, 19-25. https://doi.org/10.1053/j.semtcvs.2008.01.003

[25] Robison, P.D., Harman, P.K., Trinkle, J.K. and Grover, F.L. (1988) Management of penetrating lung injuries in civilian practice. The Journal of Thoracic and Cardiovascular Surgery, 95, 184-190. https://doi.org/10.1016/S0022-5223(19)35353-X

[26] Unsworth, A., Curtis, K. and Asha, S.E. (2015) Treatments for Blunt Chest Trauma and Their Impact on Patient Outcomes and Health Service Delivery. Scandinavian Journal of Trauma, Resuscitation and Emergency Medicine, 23, Article No. 17. https://doi.org/10.1186/s13049-015-0091-5

[27] Ekpe, E.E. and Eyo, C. (2014) Determinants of Mortality in Chest Trauma Patients. Nigerian Journal of Surgery, 20, 30-34.

[28] Chiumello, D., Coppola, S., Froio, S., Gregoretti, C. and Consonni, D. (2013) Noninvasive ventilation in chest trauma: Systematic review and meta-analysis. Intensive Care Medicine, 39, 1171-1180. https://doi.org/10.1007/s00134-013-2901-4

[29] Kallet, R.H. (2004) Evidence-Based Management of Acute Lung Injury and Acute Respiratory Distress Syndrome. Respiratory Care, 49, 793-809. 


\section{Appendix: Questionnaire}

1) General information

a) Patient's file number

b) Gender

Male $\square$ Female $\square$

c) Age

d) Marital status

e) Education level

f) Time of injury

g) Time at admission

h) Time at management

2) Vital signs at admission

a) Pulse rate

b) Respiratory rate

c) Blood pressure.

d) $\mathrm{Spo} 2$

3) Type of injury

Blunt $\square$ Penetrating $\square$

4) Mode of injury

a) Road traffic accidents

b) Fall from a height

c) assault

d) compression by heavy objects

e) blast

f) Others

5) which part of the body is injured

a) head

b) Chest

c) Extremity

d) Abdomen

e) Pelvis

f) others

6) Any preexisting comorbid conditions?

Yes-specify; Cardiac disease.

Respiratory disease.

Liver disease.

Cancer.

Neurological disease

No

7) Screening for chest injury

a) Any chest pain or difficulty in breathing?

If yes, proceed to question 8

If no, end here 
8) Findings on chest examination

Inspection.

Palpation

Percussion.

Ascultation...

9) Investigations done

a) $\mathrm{ABG}$

Yes $\square$, Results

No $\square$

b) CXR

c) Chest USS

d) Chest CT-scan

10) Pattern of chest injury

a) pneumothorax

b) hemothorax

c) pneumohemothorax

d) lung contusion

e) rib fracture

f) clavicle fracture

g) chest wall contusion

h) others

specify

11) Chest involvement

a) Unilateral..........

b) Bilateral.............

12) $\mathrm{AIS}_{\text {thorax }}$

a) 1

b) 2

c) 3

d) 4

e) 5

f) 6

13) Options used for analgesia:

a) opioids

b) non opioids

c) a and b

d) multimodal

Assessment of adequacy of analgesia

a) verbal analog scale

b) visual analog scale

c) others; ....

14) Ventilation modes;

a) Invasive Ventilation.

b) Noninvasive ventilation 
If Invasive Ventilation, what is the length of mechanical ventilation (days)........ Vital signs after ventilation
a) $\mathrm{Spo} 2$.
b) $A B G$
c) RR.

15) Any procedure/surgery done;
a) Thoracostomy
b) Thoracotomy
c) Laparotomy
d) Others............

16) Any other treatment offered............

17) Length of hospital stay................

\section{8) Outcome}

a) Discharged.........

b) Died. 